\title{
Hip pain in childhood
}

\author{
Quadril doloroso na infância
}

Sariane Coelho Ribeiro, ${ }^{1, a}$, Kaline Silva Santos Barreto ${ }^{1, b}$, Catarina Borges Santana Alves ${ }^{2, c}$, Oswaldo Lima Almendra Neto ${ }^{1, d}$, Marcel Vieira da Nóbrega ${ }^{3, e}$, Leonardo Robert de Carvalho Braga ${ }^{1, \mathrm{f}}$

1. UDI 24 horas, Teresina, PI, Brazil. 2. Universidade Ceuma, São Luís, MA, Brazil. 3. Hospital São Carlos, Fortaleza, CE, Brazil.

Correspondence: Dra. Catarina Borges Santana Alves. Universidade Ceuma. Rua Josué Montello, 1, Renascença Il. São Luís, MA, Brazil, 65075-120. Email: medcatarinaborges@gmail.com.

a. https://orcid.org/0000-0001-8497-1186; b. https://orcid.org/0000-0003-3818-6106; c. https://orcid.org/0000-0001-5708-9219;

d. https://orcid.org/0000-0001-9414-2816; e. https://orcid.org/0000-0002-6132-1727; f. https://orcid.org/0000-0002-4222-9247.

Received 20 March 2018. Accepted after revision 8 October 2018.

How to cite this article:

Ribeiro SC, Barreto KSS, Alves CBS, Almendra Neto OL, Nóbrega MV, Braga LRC. Hip pain in childhood. Radiol Bras. 2020 Jan/Fev;53(1):63-68.

Abstract Hip pain in a child can have infectious, inflammatory, traumatic, neoplastic, or developmental causes, which can make the diagnosis challenging. Meticulous history taking and a detailed clinical examination guide the radiological investigation. In this article, we address some of the main causes of hip pain in childhood and their findings on diagnostic imaging.

Keywords: Hip joint; Pain/etiology; Arthritis, juvenile; Hip dislocation, congenital; Child, preschool; Child; Adolescent.

Resumo A dor do quadril na criança pode resultar de causas infecciosas, inflamatórias, traumáticas, neoplásicas ou de desenvolvimento, por vezes gerando desafios diagnósticos. Uma história meticulosa e um exame clínico detalhado orientam a investigação radiológica na direção apropriada. Neste artigo abordaremos algumas das principais doenças do quadril doloroso na criança e seus achados nos exames de imagem.

Unitermos: Articulação do quadril; Dor/etiologia; Artrite juvenil; Luxação congênita de quadril; Pré-escolar; Criança; Adolescente.

\section{INTRODUCTION}

Hip pain in a child is a common reason for medical consultations and often represents a diagnostic challenge, because it can have numerous causes ${ }^{(1)}$, as detailed in Table 1.

Table 1-Causes of isolated hip pain in children.

\begin{tabular}{|c|c|c|}
\hline \multicolumn{2}{|l|}{ Type } & Disorder \\
\hline \multicolumn{2}{|l|}{ Congenital* } & Hip dysplasia \\
\hline \multirow{3}{*}{\multicolumn{2}{|c|}{ Infectious }} & Osteomyelitis ${ }^{\ddagger}$ \\
\hline & & Pyomyositis \\
\hline & & Septic arthritis* \\
\hline \multirow{2}{*}{\multicolumn{2}{|c|}{ Inflammatory }} & Transient synovitis of the hip* \\
\hline & & Juvenile inflammatory arthritis \\
\hline \multirow{3}{*}{\multicolumn{2}{|c|}{ Traumatic/mechanical $^{\dagger}$}} & Epiphysiolysis \\
\hline & & Apophysitis \\
\hline & & Stress fracture \\
\hline \multirow{3}{*}{\multicolumn{2}{|c|}{ Benign $^{\dagger}$}} & Osteoid osteoma \\
\hline & & Osteochondroma \\
\hline & & Eosinophilic granuloma \\
\hline \multirow{5}{*}{ Neoplastic } & & Unicameral bone cyst \\
\hline & & Aneurysmal bone cyst \\
\hline & Malignant & Metastases ${ }^{\ddagger}$ \\
\hline & & Ewing sarcoma $^{\dagger}$ \\
\hline & & Leukemia, lymphoma $^{\dagger}$ \\
\hline
\end{tabular}

*Typically present in children under 10 years of age. ${ }^{\dagger}$ Typically present in older children or adolescents ( $\geq 10$ years of age). ${ }^{\ddagger}$ Present in children of any age.
A number of studies recently conducted in Brazil have underscored the important role that imaging methods play in the evaluation of the musculoskeletal system ${ }^{(2-7)}$. Accurate diagnosis of pediatric hip disorders is essential for the characterization of early musculoskeletal changes ${ }^{(8)}$. The diagnostic imaging methods employed in the evaluation of hip pain are characterized in Table 2 .

Table 2-Imaging methods for the diagnosis of hip pain in children.

\begin{tabular}{ll}
\hline X-ray & $\begin{array}{l}\text { Initial method for evaluation of bone diseases } \\
\text { Ultrasound }\end{array}$ \\
& $\begin{array}{l}\text { Complementary to X-ray for better assessment of } \\
\text { soft tissues and detection of joint effusion; useful } \\
\text { for guiding punctures }\end{array}$ \\
Magnetic resonance & $\begin{array}{l}\text { Evaluation of complications, prolonged complaints, } \\
\text { imaging (MRI) }\end{array}$ \\
$\begin{array}{l}\text { and extent of disease; better joint detailing; and } \\
\text { evaluation of the physeal cartilage, subchondral } \\
\text { bone, periosteum, synovia, and bone marrow }\end{array}$ \\
$\begin{array}{l}\text { When there is suspicion of osteoid osteoma and for } \\
\text { tomography (CT) }\end{array}$ & $\begin{array}{l}\text { Wvaluation of the bone contours } \\
\text { Bone scintigraphy there is suspicion of osteomyelitis and the } \\
\text { primary site is unknown; for the assessment of mul- } \\
\text { tifocal disease; and for detection of osseous lesions } \\
\text { caused by stress/failure }\end{array}$ \\
\hline
\end{tabular}

\section{DISCUSSION}

The common causes of hip pain in childhood include congenital disorders and developmental dysplasia, as well as infectious, inflammatory, traumatic, rheumatologic, and neoplastic processes $^{(1)}$. 


\section{Congenital disorders}

Hip dysplasia

Hip dysplasia is characterized as an abnormal ratio between the femoral head and the acetabulum ${ }^{(9)}$. Suspicion of the condition usually arises during the first 30 days of life. For infants $\leq 6$ months of age, Graf's method of ultrasound exam can be used for screening and confirmation, thus allowing early preventive treatment to be provided ${ }^{(9)}$.

On X-rays of infants with suspected hip dysplasia, we should look for symmetry of the hips by tracing the Hilgenreiner, Perkin and Shenton lines, as well as measuring the acetabular angle (Figure 1). Findings on X-rays suggest established dysplasia ${ }^{(10)}$. CT and MRI of the hip are useful in treatment planning, monitoring, and postoperative evaluation (Figure 1).

If left untreated, hip dysplasia can evolve to abnormalities of gait, discrepancies in the length of the limbs, early osteoarthritis, and avascular necrosis ${ }^{(9)}$ (Figure 2).

\section{Infectious processes}

Among the infectious diseases that can affect children are osteomyelitis, pyomyositis, and septic arthritis. The most common infectious agents are Staphylococcus aureus in children and Streptococcus agalactiae in neonates. These pathogens spread either by hematogenous dissemination or by direct or indirect contamination ${ }^{(1)}$.
The clinical presentation of infectious diseases in children includes pain, local edema, fever with biochemical changes (increases in the erythrocyte sedimentation rate and C-reactive protein level), positive culture, and, in the case of pyomyositis, increased creatine phosphokinase and myoglobinuria ${ }^{(1,10)}$.

\section{Osteomyelitis/septic arthritis}

Osteomyelitis and septic arthritis often occur in the metaphyseal region of the bone marrow. Osteomyelitis typically affects males between 2 and 12 years of age, whereas septic arthritis affects children of either gender between 4 and 16 years of age ${ }^{(10)}$.

In osteomyelitis, X-rays and ultrasound are poorly sensitive in the early stages (within the first 10 days). Scintigraphy has high sensitivity but low specificity, being useful for verifying multifocality and for a diagnosis of exclusion when negative ${ }^{(10)}$. Bone destruction, cortical erosion, and periosteal reaction are all better visualized on CT scans. In the absence of trauma, a fat-fluid level is suggestive of osteomyelitis ${ }^{(10)}$. MRI is quite effective in the early diagnosis of osteomyelitis, as well as in assessing the extent of bone, soft tissue, and articular involvement. Osteomyelitic lesions show a hypointense signal on T1-weighted sequences and a hyperintense signal on fluid-sensitive sequences. In the post-contrast
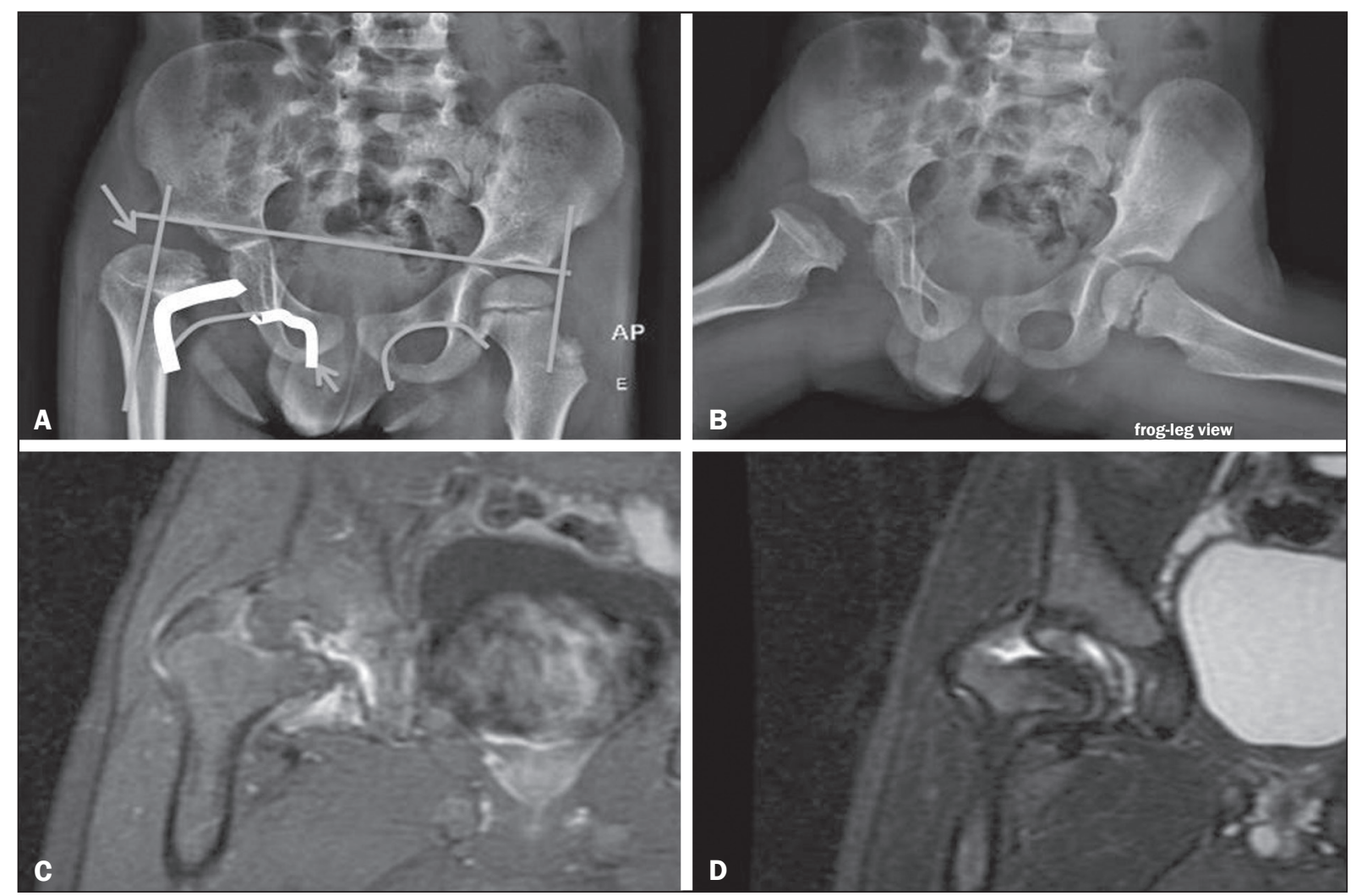

Figure 1. Dysplasia of the right hip in a 4 year-old male. Anteroposterior and frog-leg view X-rays (A and B, respectively), showing asymmetry of the hip joints, with right hip dysplasia. MRI of the right hip. Gadolinium-enhanced coronal, fat-suppressed T1-weighted sequence (C) and STIR sequence (D) showing a loss of sphericity, flattening, and superolateral subluxation of the right femoral head, with enlargement of the femoral neck and acetabular cavity, as well as joint effusion with signs of reactive synovitis. 


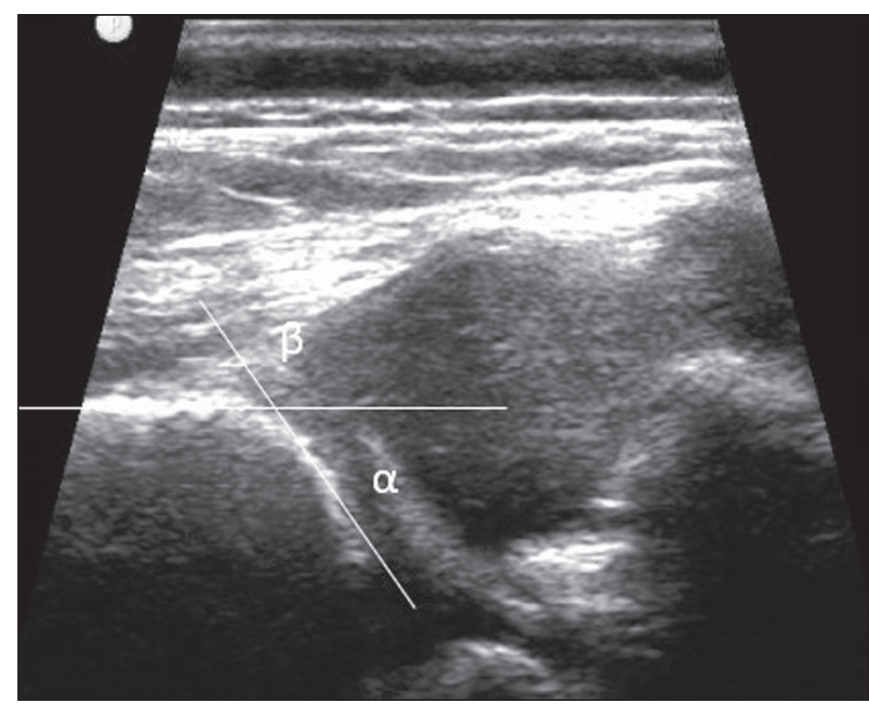

Figure 2. A 40-day-old child presenting left hip dysplasia, characterized by a alpha angle $<60^{\circ}$. phase (Figure 3), MRI detects collections in soft, subperiosteal, and intraosseous tissues, with marginal contrast enhancement, as well as areas of osteonecrosis and fistulous tracts ${ }^{(10)}$.

\section{Pyomyositis}

Pyomyositis is a bacterial infection of the muscle. It typically affects children 5-9 years of age and is more common in males ${ }^{(11)}$.

Ultrasound is useful in detecting muscle abscesses, although the findings can be unremarkable in the early stages of pyomyositis and osteomyelitis ${ }^{(11)}$. CT is not sufficiently sensitive to evaluate soft tissues or to differentiate between abscesses and hematomas ${ }^{(11)}$. MRI is the best examination for early diagnosis of soft-tissue disorders, as well as for concomitant arthritis or osteomyelitis, upon evaluation of contrast-enhanced fluid-sensitive sequences (Figure 4) ${ }^{(11)}$.

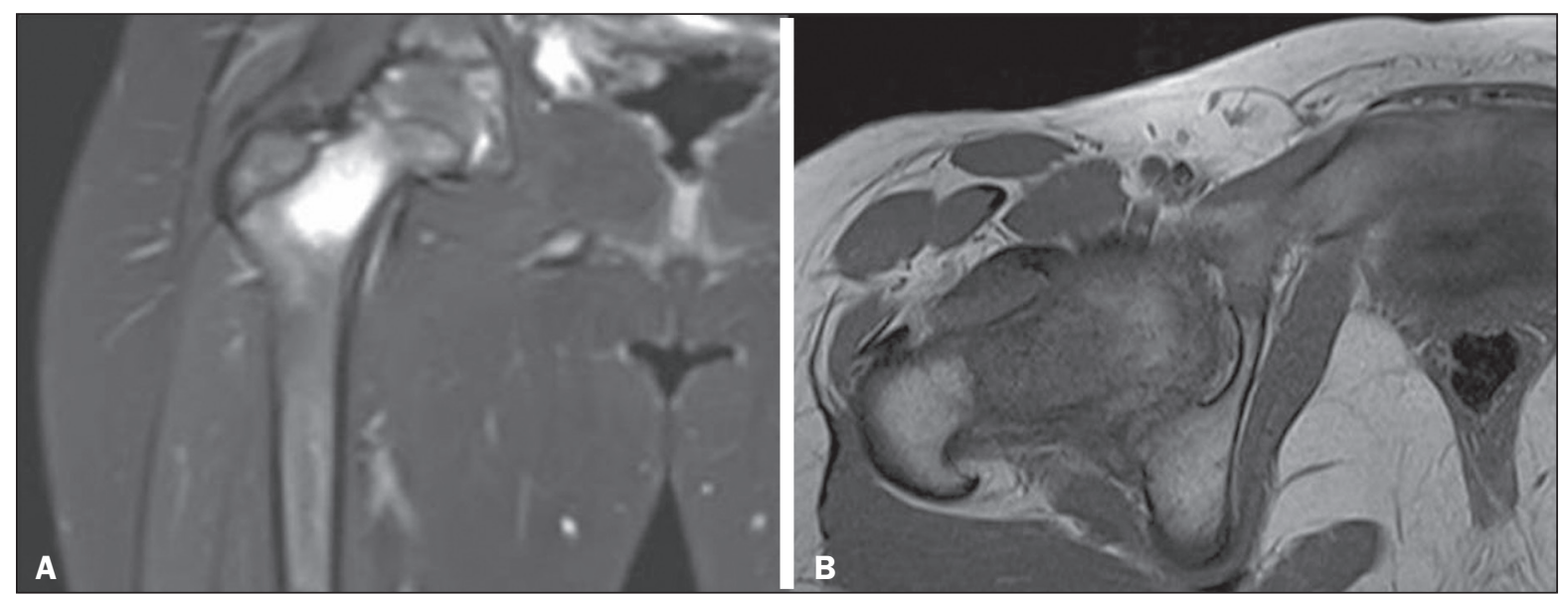

Figure 3. Osteomyelitis in a 9-year-old female. MRI of the right thigh. Coronal fat-suppressed T2-weighted sequence (A) and axial T1-weighted sequence (B) identifying an area in the marrow of the right femoral neck and extending to adjacent muscle planes, with a hypointense signal on the T1-weighted sequence, a hyperintense signal on the T2-weighted sequence, a mild periosteal reaction, and no erosion of cortical bone.

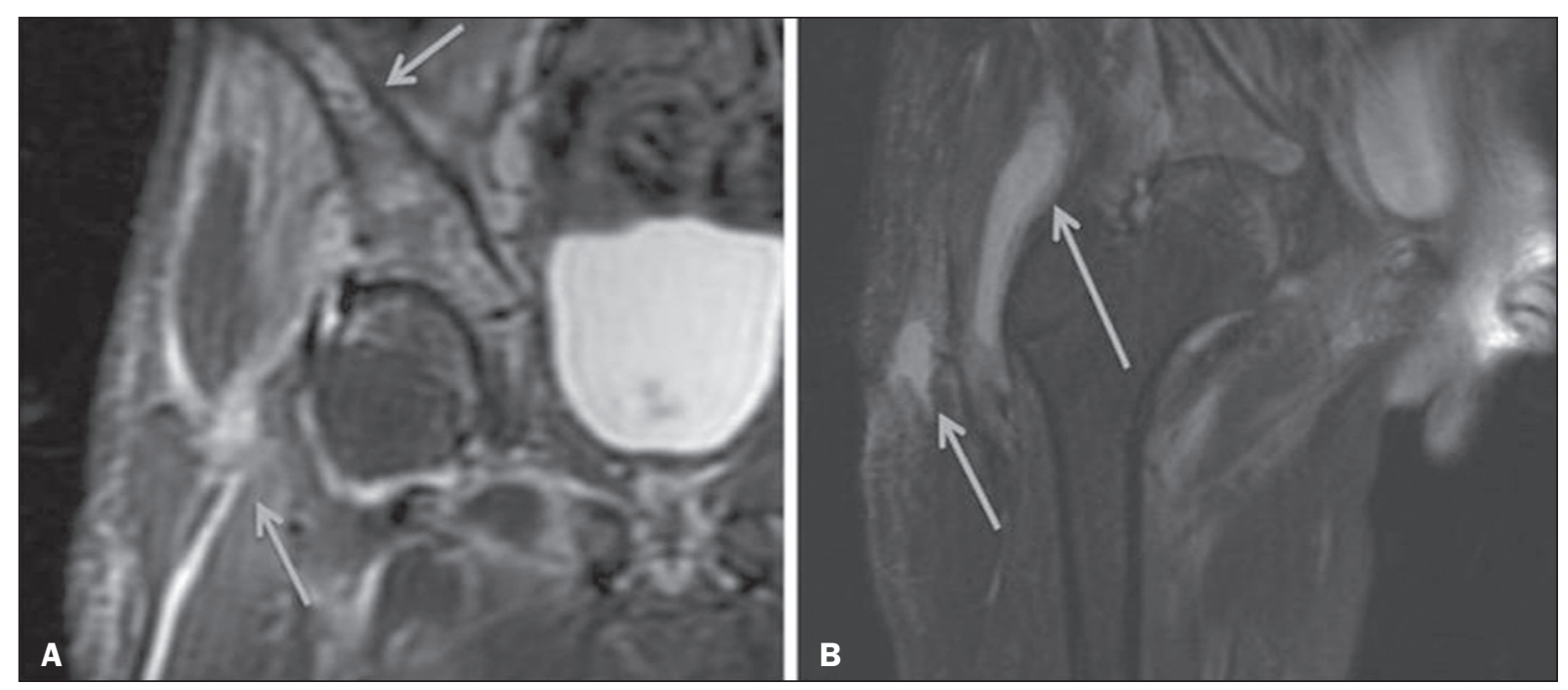

Figure 4. Pyomyositis in a 12-year-old male patient. Coronal fat-saturated T2-weighted MRI sequence showing joint effusion, osteitis, and edema involving the muscle-adipose planes of the gluteal region and root of the right thigh (A), featuring a voluminous, heterogeneous liquid collection, containing small foci of low signal intensity, likely of an infectious/inflammatory nature, located between the ventral portion of the gluteus medius muscle and that of the gluteus maximus muscle (B). 
The X-ray findings in infectious arthritis include joint effusion, periarticular osteoporosis, reduction of the joint space, bone erosion, bone destruction, and, occasionally, ankylosis (late changes) and radiolucent foci, together with periosteal reactions or heterotopic bone formations ${ }^{(10)}$. Ultrasound is useful for guiding aspiration biopsy and detecting joint effusion. Scintigraphy is useful for determining the location and distribution of infectious processes $^{(10)}$. As illustrated in Figure 5, MRI facilitates the detection of synovitis, inflammatory changes, and periarticular collections ${ }^{(10)}$.

The differential diagnosis of septic arthritis primarily includes transient synovitis of the hip and arthritis caused by rheumatoid or hematological diseases.

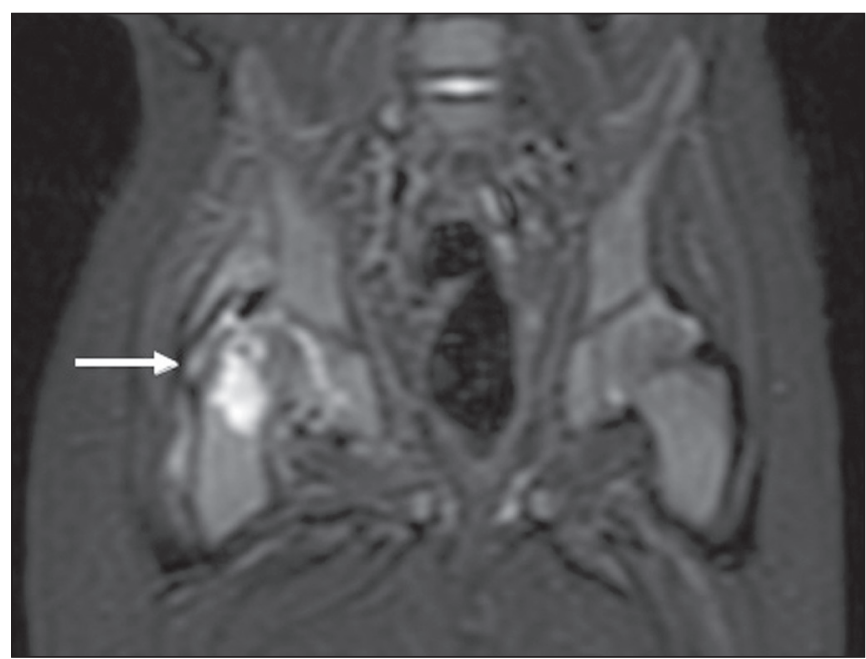

Figure 5. MRI of the hip. STIR coronal sequence showing mild effusion in the right hip joint, with synovial thickening and hyperintense signal/edema in the adjacent planes of the capsule of the muscle. Note the irregular lesion, with a hyperintense signal in a T2-weighted sequence, in the right femoral head and neck, which is suggestive of a focus of osteomyelitis/intraosseous abscess.

\section{Inflammatory processes}

\section{Transient synovitis}

Transient synovitis of the hip is a benign condition, of unknown origin, that is self-limited. It accounts for approximately $90 \%$ of cases of hip pain in children. The majority of cases are in individuals with a history of upper respiratory tract infection (approximately two to three weeks before the onset of symptoms) or mild trauma. The age at onset ranges from 18 months to 13 years, most cases occurring in individuals between 3 and 8 years of $\operatorname{age}^{(8)}$.

The diagnosis is made by exclusion. Ultrasound reveals anechoic joint effusion or with fine debris (Figure 6). An X-ray can show enlargement of the joint space and helps exclude other disorders of the hip. Other imaging exams are usually unnecessary. In cases in which there is suspicion of an infectious process, joint puncture is indicated $^{(8)}$. The MRI findings include unilateral or bilateral joint effusion, as well as mild synovial thickening and

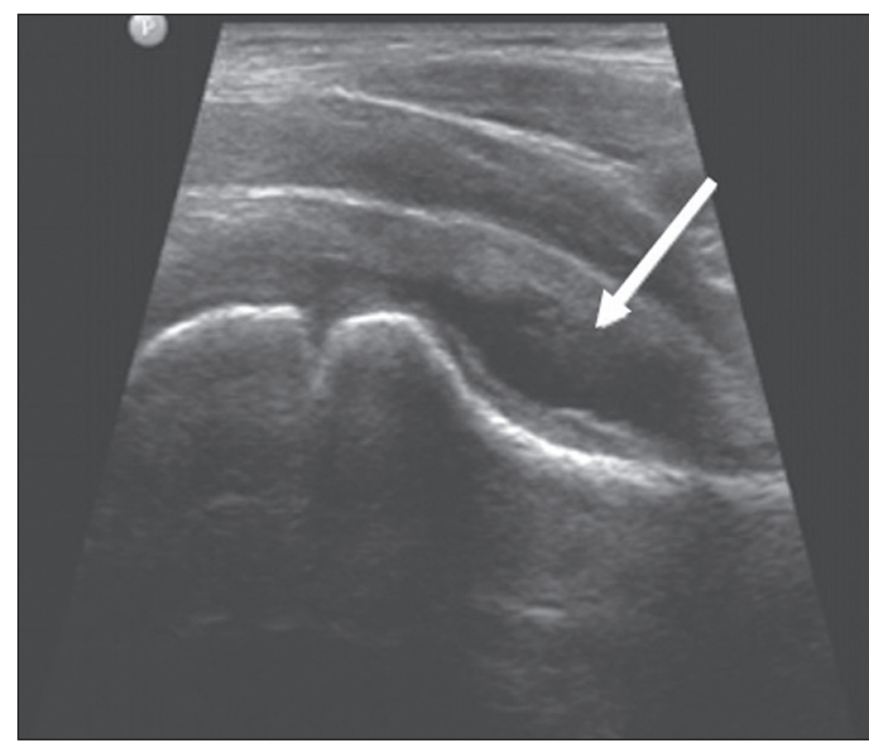

Figure 6. Ultrasound of the hip identifying joint effusion.

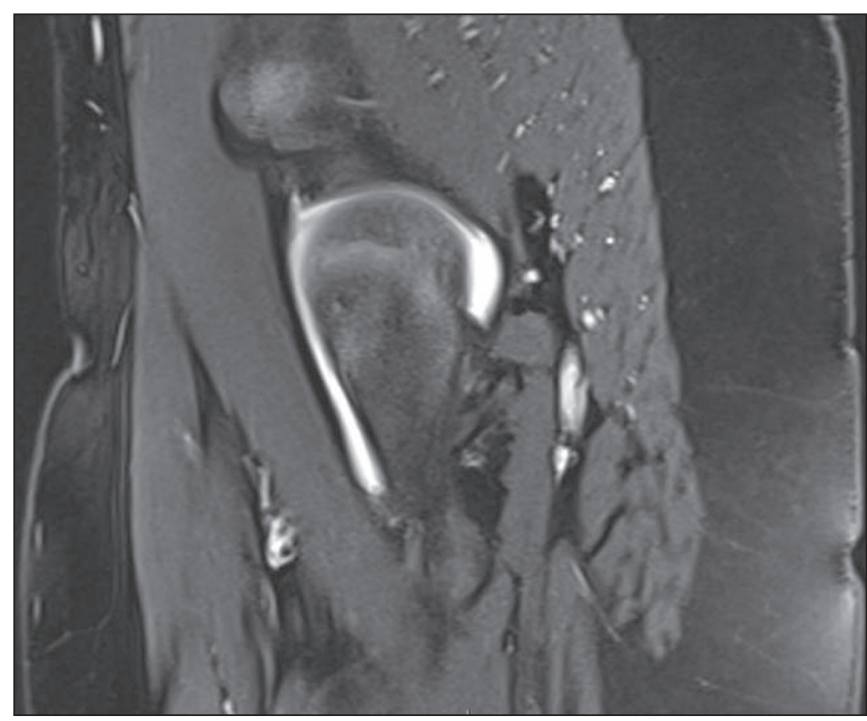

Figure 7. A 12-year-old male patient. Sagittal fat-saturated T2-weighted MRI sequence showing moderate intra-articular effusion in the right hip joint.

enhancement. As can be seen in Figure 7, there is usually no clear alteration of the bone signal ${ }^{(12)}$.

\section{Trauma}

Epiphysiolysis

Epiphysiolysis is best described as a fracture of the growth plate with a slipped capital femoral epiphysis (equivalent to a Salter-Harris type I fracture). It is the most common abnormality of the hip in overweight male adolescents $^{(10)}$.

On MRI, epiphysiolysis presents as focal or diffuse physeal enlargement, best defined in coronal or axial T1weighted sequences, together with irregularity and a hyperintense signal caused by bone marrow edema (Figure 8).

Avascular necrosis of the femoral head occurs in approximately $15 \%$ of patients with epiphysiolysis. The 


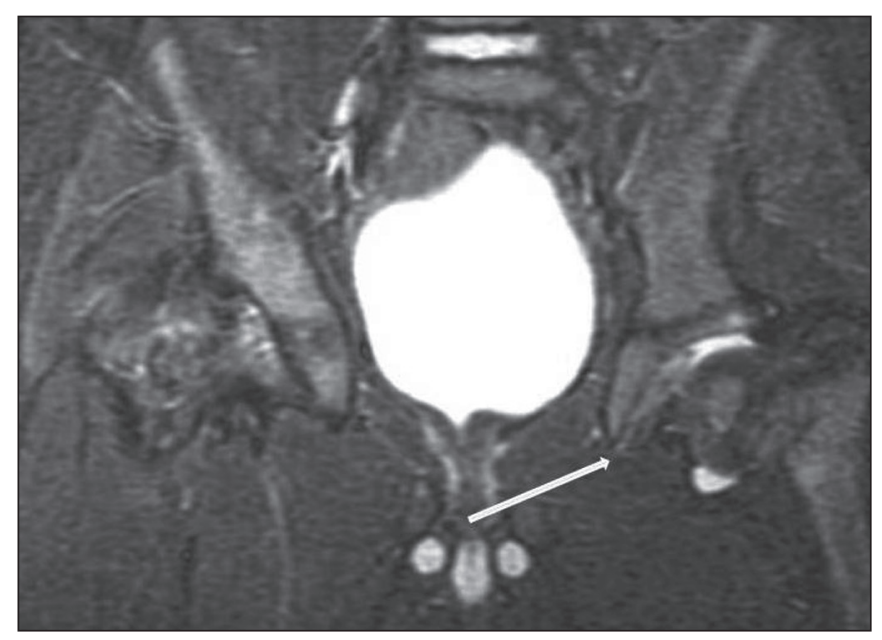

Figure 8. MRI of the hip. STIR coronal sequence showing signs of pronounced epiphysiolysis. Note the moderate joint effusion.

alterations caused by such necrosis include the crescent sign, juxta-articular sclerosis, cystic areas, flattening, fragmentation, and collapse of the femoral head. Necrosis typically involves the anterolateral femoral head ${ }^{(13)}$. Late complications include pistol-grip deformity (enlargement and shortening of the femoral neck and varus deformity), degenerative osteoarthritis, and limb-length discrepancy resulting from physeal fusion (Figure 9).

MRI is useful in diagnosing pre-epiphysiolysis conditions, when there is no objective sign of femoral head displacement. It is recommended that both hips be evaluated, because epiphysiolysis is bilateral in up to $50 \%$ of cases $^{(13)}$.

\section{Apophysitis/osteochondritis}

Sites of tendon attachment (apophyses) are sensitive to repetitive traction. The apophyses are subject to traction apophysitis or osteochondritis at the insertion site ${ }^{(13)}$. Either can compromise the development of ossification

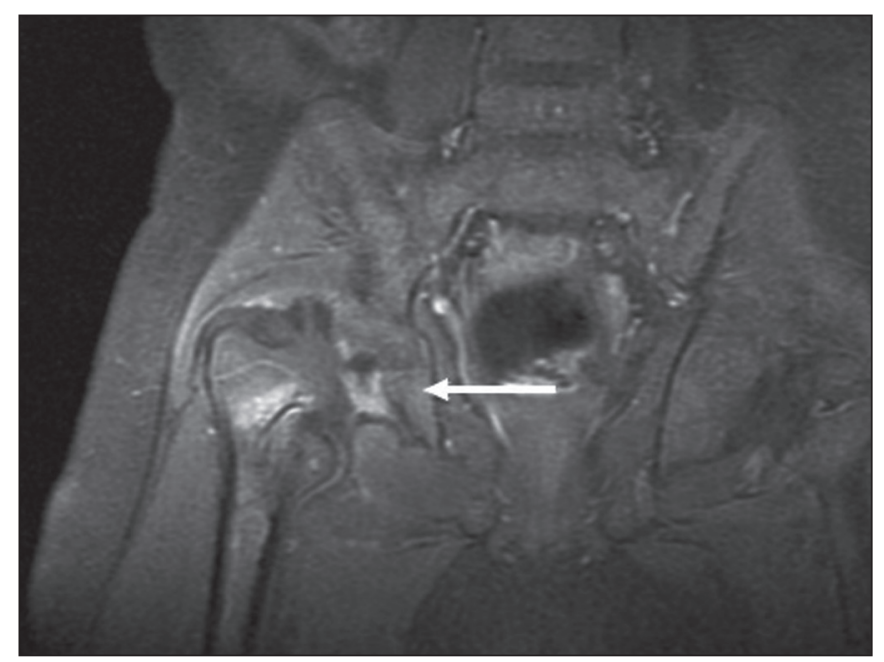

Figure 9. MRI of the hip. Contrast-enhanced, coronal, fat-saturated T1-weighted sequence showing complete destruction/resorption of the femoral head, accompanied by severe deformity of the femoral neck and acetabulum. nuclei of the apophyses, with fragmentation and an increase in volume ${ }^{(13)}$. The pelvic sites most commonly involved are the iliac crest, anterosuperior iliac spine, the anteroinferior iliac spine, and the ischial tuberosity, as well as the lesser and greater trochanters ${ }^{(14)}$.

In the acute phase of apophysitis, X-rays are useful for confirming the presence of incipient apophysitis, documenting the avulsion or fragmentation of a given apophysis, and ruling out other bone abnormalities such as epiphyseal fractures ${ }^{(15)}$. In patients with apophysitis and no avulsion, X-rays appear normal. Although the MRI findings of apophysitis can be variable, the initial findings include low signal intensity on T1-weighted sequences with increased signal intensity in fluid-sequences, bone marrow edema, and mild enlargement of the physis (Figure 10). After healing, there can be hypertrophic ossification and residual sclerosis ${ }^{(14)}$.

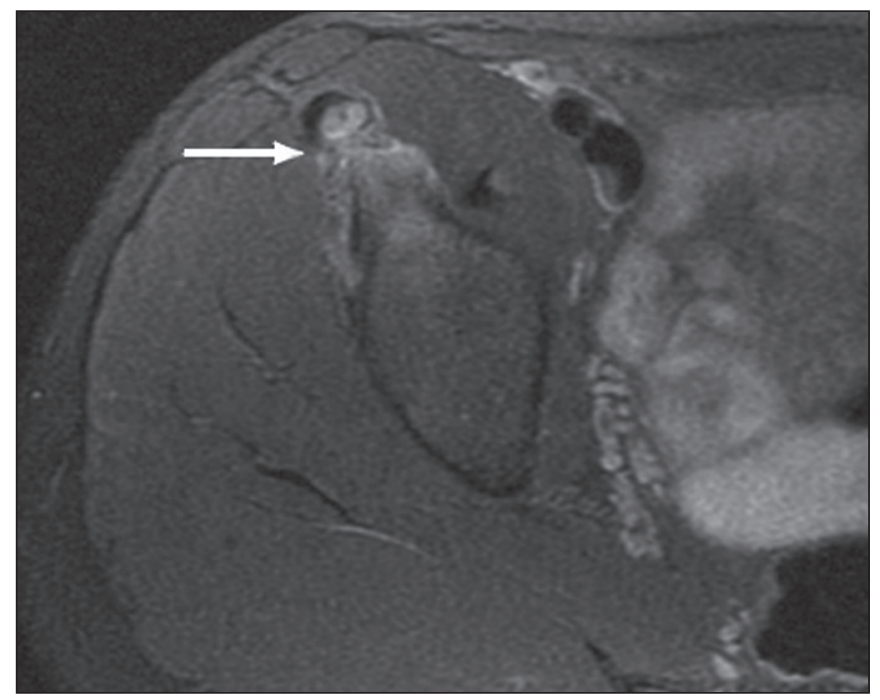

Figure 10. A 14-year-old male. Axial proton density-weighted fat-saturated MRI showing bone edema in the right anteroinferior iliac spine.

\section{CONCLUSION}

The differential diagnoses of hip pain in the pediatric population are myriad. Therefore, timely, accurate diagnosis is essential to ensure early, effective treatment.

In pediatric patients with hip pain, a measured approach to diagnostic imaging, contextualized by clinical and laboratory data, helps identify the correct diagnosis, avoid unnecessary interventions, properly manage cases, and prevent complications in adulthood.

\section{REFERENCES}

1. Zucker EJ, Lee EY, Restrepo R, et al. Hip disorders in children. AJR Am J Roentgenol. 2013;201:W776-96.

2. Nascimento PCX, Amaral AM, Almeida JRM. Magnetic resonance arthrography of the shoulder: a painful procedure? Radiol Bras. 2018;51:81-6.

3. Kubo RS, Kihara Filho EN, Fonseca EKUN, et al. Overuse of the hip external rotators: greater trochanter apophysitis in the karate kid. Radiol Bras. 2018;51:345-6. 
4. Canella C, Costa F, Danowisk A, et al. Stress fracture and osteomyelitis in a patient with systemic lupus erythematosus. Radiol Bras. 2018;51:277-8.

5. Costa FM, Canella C. Vieira FG, et al. The usefulness of chemicalshift magnetic resonance imaging for the evaluation of osteoid osteoma. Radiol Bras. 2018;51:156-61.

6. Werneck L, Canella C, Costa F, et al. Usefulness of dynamic contrast-enhanced MRI in the evaluation of osteonecrosis of the proximal fragment in scaphoid fractures. Radiol Bras. 2018;51:334.

7. Moreira FP, Aihara AY, Lederman HM, et al. Cognitive map to support the diagnosis of solitary bone tumors in pediatric patients. Radiol Bras. 2018;51:297-302.

8. Zoner CS, Narahashi E, Honda E, et al. Quadril doloroso da criança. Rev Bras Reumatol. 2005;45:389-95.

9. Starr V, Ha BY. Imaging update on developmental dysplasia of the hip with the role of MRI. AJR Am J Roentgenol. 2014;203:132435.

\section{$(\infty)) E_{Y}$}

10. Muller CIS, D’Ippolito G, Rocha AJ. Musculoesquelético. Série Colégio Brasileiro de Radiologia e Diagnóstico por Imagem. $1^{\text {a }}$ ed. São Paulo, SP: Elsevier; 2014.

11. Gonzalez Moran G, Garcia Duran C, Albiñana J. Imaging on pelvic pyomiositis in children related to pathogenesis. J Child Orthop. 2009; 3:479-84.

12. Murphy A, Weerakkody Y. Transient synovitis of the hip. [cited 2017 Nov 15]. Available from: https://radiopaedia.org/articles/transientsynovitis-of-the-hip.

13. Guzmán PH. Lesiones deportivas en niños y adolescentes. Rev Med Clin Condes. 2012;23:267-73.

14. Concannon LG, Standaert CJ, Rothmier JD. Apophysitis of the posterior superior iliac spine associated with lumbar spondylolysis in a high school athlete. PMR. 2011;3:387-90.

15. Fernandes JL, Viana SL, Mendonça JLF, et al. Avulsão da espinha ilíaca ântero-inferior: espectro dos achados de imagem. Rev Imagem. 2005;27:207-12. 